\title{
Evaluation of the changes in physicochemical and antioxidant properties of honey during storage
}

\author{
Mehdi Zarei, Ali Fazlara, Nasim Alijani
}

Department of Food Hygiene, Faculty of Veterinary Medicine, Shahid Chamran University of Ahvaz, Ahvaz, Iran

Corresponding author: Mehdi Zarei, $\mathrm{PhD}$, Department of Food Hygiene, Faculty of Veterinary Medicine, Shahid Chamran University of Ahvaz, Ahvaz, Iran.

Submission Date: May $13^{\text {th }}$, 2019. Acceptance Date: September 27 ${ }^{\text {th }}$, 2019. Publication Date: September $30^{\text {th }}, 2019$.

Citation: Zarei M., Fazlara A., Alijani N. Evaluation of the changes in physicochemical and antioxidant properties of honey during storage. Functional Foods in Health and Disease 2019; 9(9): 593-605. DOI: https://doi.org/10.31989/ffhd.v9i9.616

\begin{abstract}
Background: Despite having a lot of information about the physicochemical and antioxidant properties of honey from different geographical regions, there is only limited information about the changes in these characteristics during long-term storage of honey. Hence, this study was conducted to evaluate these changes in five different types of honey, including alfalfa, milkvetch, lotus, thyme, and multifloral honey, during one year of storage at room temperature.
\end{abstract}

Methods: Samples were analyzed for $\mathrm{pH}$, free acidity, Ash, moisture, electrical conductivity, hydroxymethylfurfural, color, total phenolic content, DPPH radical-scavenging activity and ferric reducing antioxidant power.

Results: Changes were observed in all the physicochemical characteristics of honey during the storage period. However, these changes did not exceed the maximum acceptable limits and after one-year of storage, the physicochemical properties of all types of honey were within the standard limits except for HMF content in multifloral honey $(43.89 \mathrm{mg} / \mathrm{kg}$ ). Regarding the antioxidant capacity of honey, our results showed 38.92-73.3 \% decrease in DPPH radical scavenging activities and 43.29-67.0 \% decrease in FRAP values of different types of honey during the storage period.

Conclusion: From a nutritional point of view, a decrease in the antioxidant capacity of honey is of particular importance. Therefore, these levels of reduction in antioxidant capacity could certainly affect the nutritional and health benefits of honey.

Keywords: Honey; Physicochemical; Antioxidant capacity; Changes; Storage 


\section{INTRODUCTION}

Honey, as a natural product, contains a complex mixture of simple sugars (mainly fructose and glucose) and other less frequent substances, such as amino acids, minerals, organic acids, proteins, lipids, vitamins, aroma compounds, pigments, waxes, pollen grains and other phytochemicals. In addition, honey serves as a source of natural antioxidants which play an important role in human health by reducing the risk of heart disease, cancer, cataracts, immunesystem decline and different inflammatory processes [1-4]. The physicochemical characteristics and the quantity of the components responsible for antioxidant activity of honey vary widely depending on the source plant, climate and environmental condition, bees' species, the contribution of the beekeeper and treatment of honey during extraction and storage [5].

In past years, many studies have been conducted to determine the physicochemical and antioxidant properties of various types of honey from around the world [1, 3, 6-8]. However, there is only scarce information about the changes in physicochemical and antioxidant properties of honey during storage. Since honey is frequently not consumed immediately after production, it is important to address this issue.

The main objective of this study is to evaluate the changes in physicochemical and antioxidant properties of honey during one year of storage.

\section{MATERIALS AND METHODS}

\section{Honey samples}

A total of 25 commercial honey samples from different floral sources was collected directly from the beekeepers. Honey samples consisted of five samples from each of alfalfa (Medicago sativa), milkvetch (Astragalus hamosus), lotus (Ziziphus lotus), thyme (Zataria multiflora), and multifloral honey. Honey were stored for one year in transparent plastic containers at room temperature, on shelves exposed to natural light during daytime and in the dark at night. Samples were taken every 3 months and physicochemical and antioxidant properties were evaluated.

\section{Physicochemical analysis \\ pH}

Honey $\mathrm{pH}$ was measured using a $\mathrm{pH}$-meter (Sartorius Ag, Goettingen, Germany) in a solution prepared with $10 \mathrm{~g}$ of honey in $75 \mathrm{ml}$ of distilled water [3].

\section{Free acidity}

Ten grams of honey were dissolved in $75 \mathrm{ml}$ of distilled water in a $250 \mathrm{ml}$ beaker, and $100 \mu \mathrm{l}$ of $1 \%$ alcoholic solution of phenolphthalein added. The solution was titrated with $0.1 \mathrm{~N} \mathrm{NaOH}$. Free acidity was determined as 10 times the volume of $\mathrm{NaOH}$ used in titration and expressed as milliequivalent of acid $/ \mathrm{kg}$ of honey [3].

\section{Electrical conductivity}

Electrical conductivity (EC) was measured at $20{ }^{\circ} \mathrm{C}$ in solutions of honey samples containing 10 $\mathrm{g}$ of honey in $75 \mathrm{ml}$ of distilled water, using the conductivity meter (8301 Conductivity meter, AZ Instrument Corp.) and expressed as $\mu \mathrm{S} / \mathrm{cm}^{-1}[3,9]$. 
Ash

The total ash content was indirectly determined using the measured electrical conductivity and applying the following equation: [9]. Ash $(\%)=[(0.083 \times$ Electrical conductivity $) / 100]-0.092$

\section{Moisture}

The moisture content was determined by measuring refractive index using an Abbe refractometer (2WAJ Abbe refractometer, Bluewave Industry Co. Ltd.), and obtaining the corresponding \% moisture (g/100 $\mathrm{g}$ honey) by consulting the standard table [10].

\section{Hydroxymethylfurfural (HMF)}

The standard AOAC method was used to determine Hydroxymethylfurfural content of the honey samples [10]. Briefly, 5 grams of honey were dissolved in $25 \mathrm{ml}$ of distilled water, treated with $500 \mu \mathrm{l}$ of Carrez I and $500 \mu \mathrm{l}$ of Carrez II solutions and then the volume made up to $50 \mathrm{ml}$. The solution was filtered, and the first $10 \mathrm{ml}$ discarded. The absorbance of the filtered solution was measured at 284 and $336 \mathrm{~nm}$ against an aliquot of the filtered solution treated with $\mathrm{NaHSO}_{3}$. HMF was determined using the following equation:

$$
\mathrm{HMF}(\mathrm{mg} / \mathrm{kg})=\left[\left(\mathrm{A}_{284}-\mathrm{A}_{336}\right) \times 149.7 \times 5\right] / \text { Weight of sample }
$$

\section{Color intensity}

Honey samples were diluted to $50 \%(\mathrm{w} / \mathrm{v})$ with warm $\left(50{ }^{\circ} \mathrm{C}\right)$ distilled water; in order to dissolve sugar crystals. The absorbance was measured using a spectrophotometer at $635 \mathrm{~nm}$ and the color intensity was determined using the Pfund scale: [2].

Pfund $(\mathrm{mm})=(371.39 \times$ Abs $)-38.70$

\section{Total phenolics}

The total phenolic content was determined using the Folin-Ciocalteu method, and the results were expressed as mg tannic acid/kg honey. $100 \mu \mathrm{l}$ of $50 \%$ honey solution was mixed with 1.5 $\mathrm{ml} 10 \%$ Folin-Ciocalteu reagent and $1.4 \mathrm{ml} 7.5 \%$ sodium carbonate solution. After incubation at room temperature for $30 \mathrm{~min}$, the absorbance of the reaction mixture was measured at $750 \mathrm{~nm}$ against a blank of distilled water (CECIL CE 2040 spectrophotometer 2000 series from CECIL instruments, Cambridge, England). Tannic acid was used as standard to produce the calibration curve [11].

\section{Antioxidant capacity DPPH radical-scavenging activity}

The DPPH radical scavenging activity of honey samples was determined according to the method of Brand-Williams modified by Miliauskas. The DPPH solution in methanol (0.06 mM) was prepared daily, and $2.7 \mathrm{ml}$ of this solution was mixed with $0.3 \mathrm{ml}$ of $50 \%(\mathrm{w} / \mathrm{v}$ ) honey solution. The mixture was shaken vigorously and left to stand for $60 \mathrm{~min}$ in the dark (until stable absorption values were obtained). The reduction of the DPPH radical was determined by measuring the absorption at $517 \mathrm{~nm}$. The experiment was carried out in triplicate. Radical 
scavenging activity (RSA) was calculated as a percentage of DPPH discoloration using the equation: Radical scavenging activity $(\%)=\left[\left(\mathrm{A}_{\mathrm{DPPH}}-\mathrm{A}_{\mathrm{S}}\right) / \mathrm{A}_{\mathrm{DPPH}}\right] \times 100$, where $\mathrm{A}_{\mathrm{S}}$ is the absorbance of the sample solution and $A_{D P P H}$ is the absorbance of the DPPH solution $[2,12,13]$

\section{Ferric reducing antioxidant power (FRAP)}

The procedure described by Benzie and Strain (1996) was used with minor modification [14]. Briefly, $0.2 \mathrm{ml}$ of $50 \%$ (w/v) honey solution was mixed with $2.8 \mathrm{ml}$ of daily-prepared FRAP reagent containing $2.5 \mathrm{ml}$ of a $10 \mathrm{mM}$ TPTZ (2,4,6-tripyridyl-s-triazine) solution in $40 \mathrm{mM} \mathrm{HCl}$, $2.5 \mathrm{ml}$ of $20 \mathrm{mM} \mathrm{FeCl} 3$ and $25 \mathrm{ml}$ of $0.3 \mathrm{M}$ acetate buffer, $\mathrm{pH} \mathrm{3.6.} \mathrm{The} \mathrm{absorbance} \mathrm{of} \mathrm{the}$ reaction mixture was measured spectrophotometrically at $593 \mathrm{~nm}$ after incubation at $37{ }^{\circ} \mathrm{C}$ for 15 min. Aqueous standard solutions of $\mathrm{FeSO}_{4} .7 \mathrm{H}_{2} \mathrm{O}(100-1000 \mu \mathrm{M})$ were used for the calibration curve and the results were expressed as the FRAP value ( $\mu \mathrm{M}$ Fe(II)) of the $50 \%$ honey solution.

\section{Statistical analysis}

All analyses were carried out in triplicate, and the data was expressed as mean \pm standard deviation (SD). In each type of honey, the changes made in the measured parameter during the storage period, were analyzed using the Repeated Measure ANOVA (SPSS 20). The significance levels are expressed at a $95 \%$ confidence level $(\mathrm{P} \leq 0.05)$ throughout.

\section{RESULTS AND DISCUSSION}

The $\mathrm{pH}$ is a parameter that is correlated with honey storage and with microorganism growth that could change the texture and honey stability [15]. According to the Iranian national standards organization (INSO), the lowest acceptable $\mathrm{pH}$ of honey samples is 3.5 [16]. The initial $\mathrm{pH}$ values for studied honey samples were in the range of $4.2 \pm 0.38$ (alfalfa honey) to $5.1 \pm 0.43$ (lotus honey), which were acceptable values and comparable with those obtained in other works $[3,7,8]$. As shown in Fig. 1A, during one-year storage of honey, $\mathrm{pH}$ showed a slight decline, where, at the end of storage time, 0.11 to 0.24 units of decline were observed in all types of honey $(\mathrm{P} \geq 0.05)$.

In this regard, a slight increase in free acidity of all types of honey was observed during the storage period. As shown in Fig. 1B, the initial levels of free acidity for studied honey samples were in the range of $14.01 \pm 2.7 \mathrm{meq} / \mathrm{kg}$ (lotus honey) to $25.71 \pm 2.4 \mathrm{meq} / \mathrm{kg}$ (alfalfa honey), which were acceptable values (below $40 \mathrm{meq} / \mathrm{kg}$ ) and comparable with those obtained in other works [7]. However, at the end of the storage period, a non-significant increase in free acidity was observed in all types of honey $(\mathrm{P} \geq 0.05)$. The free acidity of honey may be explained by considering the presence of organic acids in equilibrium with their corresponding lactones, or internal esters, and some inorganic ions, such as phosphate, sulfate and chloride [17].

A slight reduction in the moisture content of honey during one-year storage (Fig. 3A) and consequently, increase in the concentration of the components responsible for acidity of honey, may explain the changes in $\mathrm{pH}$ and free acidity of honey during the storage period. 
Fig. 1A

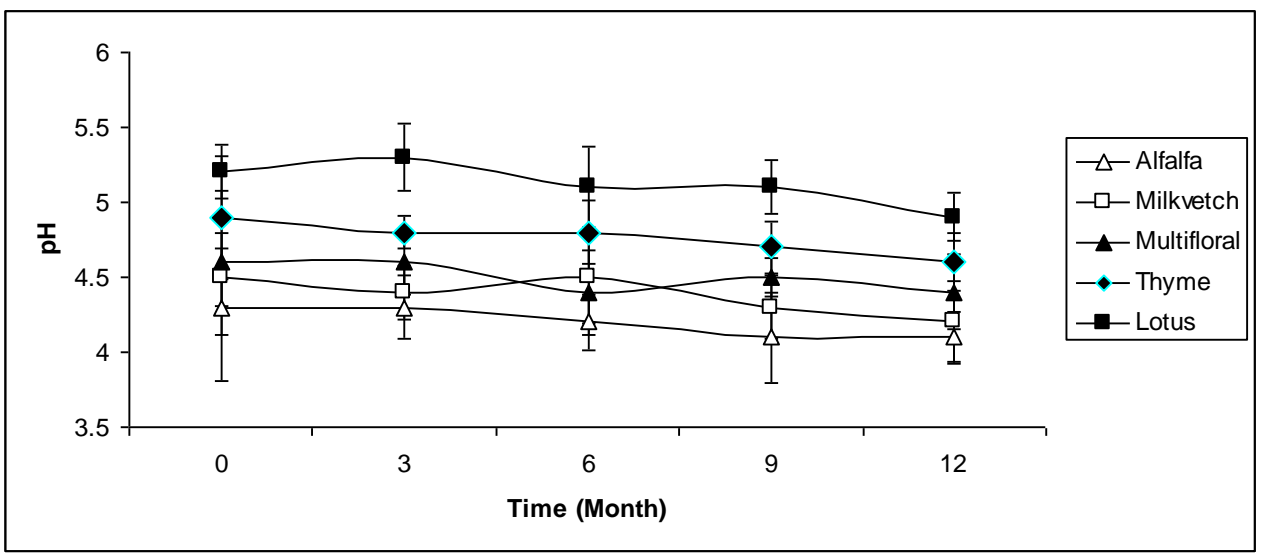

Fig. 1B

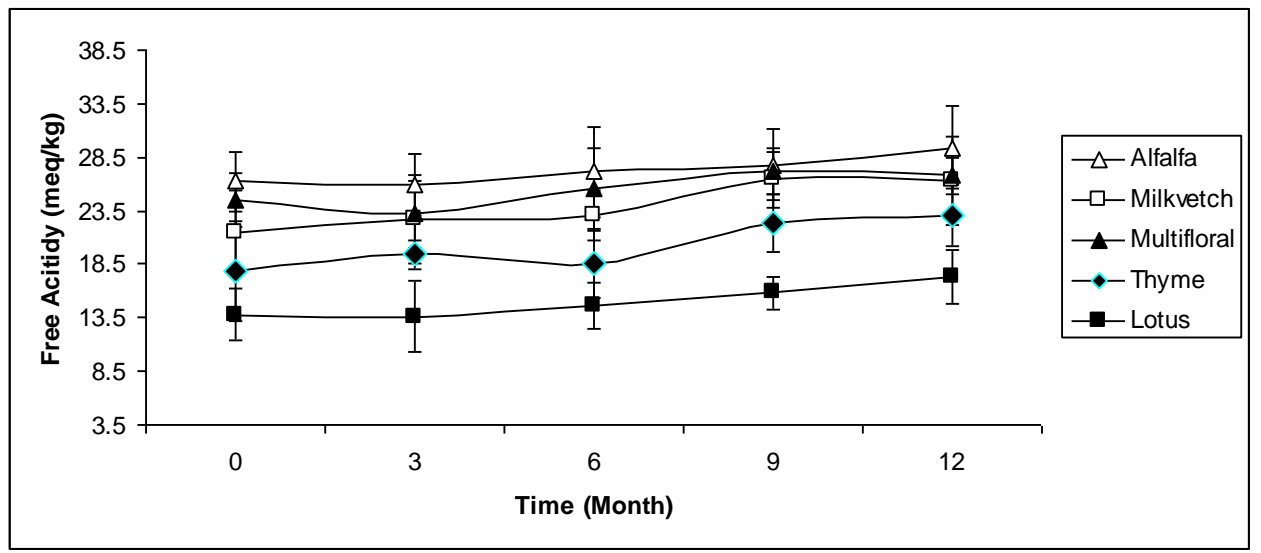

Fig. 1. Changes in pH (A) and free acidity (B) of honey during storage

The electrical conductivity of honey is closely related to the concentration of mineral salts, organic acids and proteins. This parameter shows great variability according to the floral origin and it is important for the differentiation of honey of different floral origins $[7,9]$. In the present study, none of the analyzed honey samples showed electrical conductivity values higher than 800 $\mu \mathrm{S} / \mathrm{cm}$, the maximum limit indicated by Iranian [16] and international standards [18]. The lowest initial EC level was $287.3 \pm 48.4 \mu \mathrm{S} / \mathrm{cm}$ (alfalfa honey) and the highest initial EC level was $570.1 \pm 41 \mu \mathrm{S} / \mathrm{cm}$ (lotus honey). As shown in Fig. 2A, slight increases in conductivity of all types of honey were observed at the end of storage period $(\mathrm{P} \geq 0.05)$.

Ash content is a quality criterion for the determination of the botanical origin [7, 9]. In the present work, the initial ash contents varied from $0.13 \pm 0.05 \mathrm{~g} / 100 \mathrm{~g}$ in alfalfa honey to $0.37 \pm$ $0.02 \mathrm{~g} / 100 \mathrm{~g}$ in lotus honey, which were lower than the maximum acceptable limit $(0.6 \mathrm{~g} / 100 \mathrm{~g})$ and comparable to the results of electrical conductivity; the higher is the ash content of the honey, the higher is the electrical conductivity, as previously documented in many studies [3, 7 , 19]. Similar to EC results, slight increases $(P \geq 0.05)$ in the ash content of all types of honey were observed at the end of storage period (Fig. 2B). These slight increases in ash content and EC can be due to the decrease in the moisture content of honey during storage. 
Fig. 2A

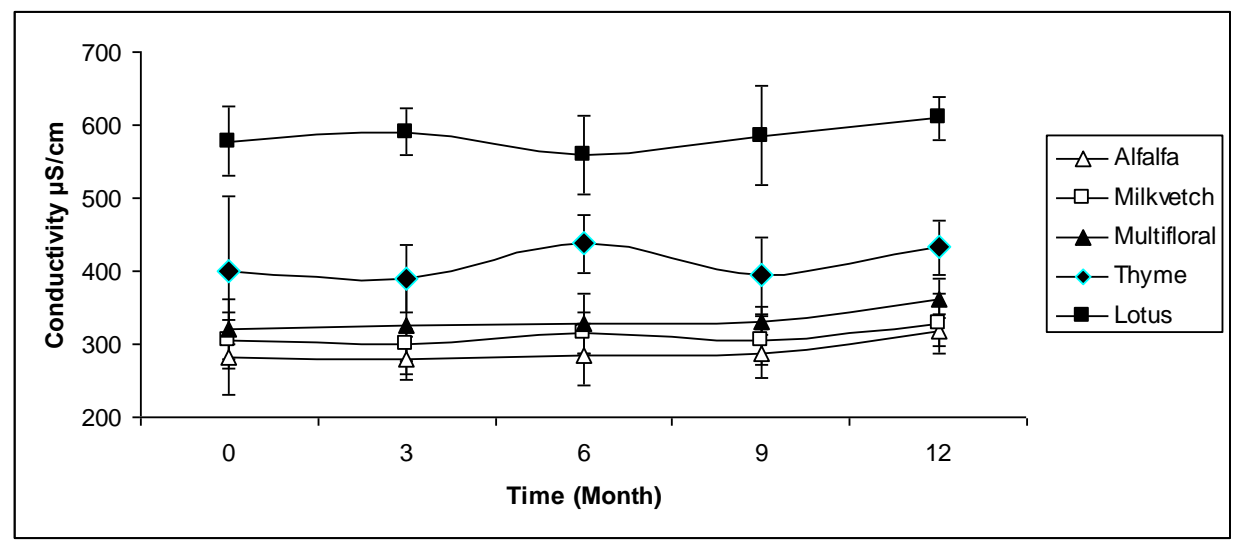

Fig. 2B

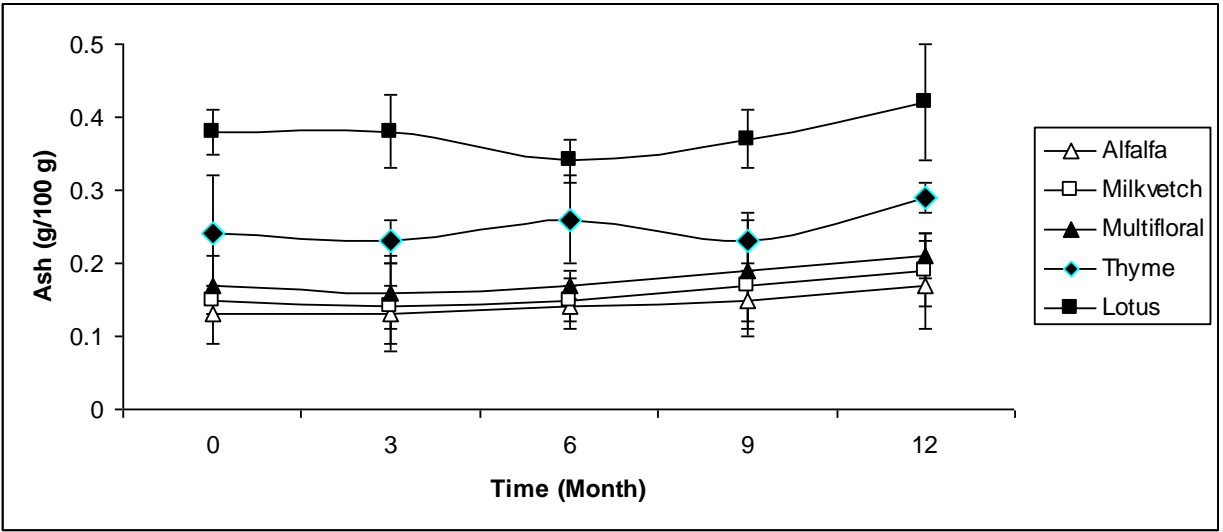

Fig. 2. Changes in electrical conductivity (A) and ash content (B) of honey during storage

Honey moisture content is dependent on the environmental conditions such as the temperature and relative humidity in the geographical origin during honey producing in honey colonies, and the manipulation from beekeepers at the harvest period [3]. Moisture content of honey is a limiting factor for determining its quality, stability and spoilage resistance against yeast fermentation. In the present study, the initial moisture contents of five types of honey samples were in the range of $16.14 \pm 0.39 \%$ in lotus honey to $17.63 \pm 1.2 \%$ in alfalfa honey, which were well below the maximum acceptable limit $(20 \%)$ determined by national and international standards $[16,18]$. During storage of honey for one year, significant changes (except for thyme honey) in moisture content of all types of honey observed (Fig. 3A), where, at the end of the storage time, a decrease of $1.05-1.93 \%$ was observed in the moisture content of all types of honey $(\mathrm{P} \geq 0.05)$.

HMF, naturally present in honey because of the action of normal honey acidity on reducing sugars, is recognized as a marker of honey freshness and quality deterioration. The HMF content tends to increase during processing and/or aging of the product. Several factors influence the levels of HMF, such as temperature and time of heating, storage conditions, $\mathrm{pH}$ and floral source, thus it provides an indication of overheating and storage in poor conditions [7, 8, 20]. In the present study, the mean values of initial HMF content in all types of honey were below the national and international legal limit $(\leq 40 \mathrm{mg} / \mathrm{kg})$, indicating freshness of the honey and good storage condition. Multifloral honey showed the highest initial level of HMF $(20.18 \pm 8.7 \mathrm{mg} / \mathrm{kg})$ and alfalfa honey showed the lowest initial level of $\operatorname{HMF}(6.41 \pm 6.9 \mathrm{mg} / \mathrm{kg})$. 
Changes in HMF content during the storage period were not the same for all types of honey. As shown in Fig. 3B, although the level of HMF in all types of honey increased during the storage period, the rate of this increase was quite different. During one-year storage period, the highest rate of HMF enhancement was observed in alfalfa and lotus honey, with more than 3 times increase, followed by milkvetch honey (almost 3 times). At the same time period, the level of HMF content in thyme and multifloral honey, increased only 1.28 and 2.17 times, respectively. Nevertheless, after one year of storage, only in multifloral honey, HMF content reached a level above the maximum acceptable limit $(43.89 \mathrm{mg} / \mathrm{kg})$, which could be due to its higher initial level.

Fig. 3A

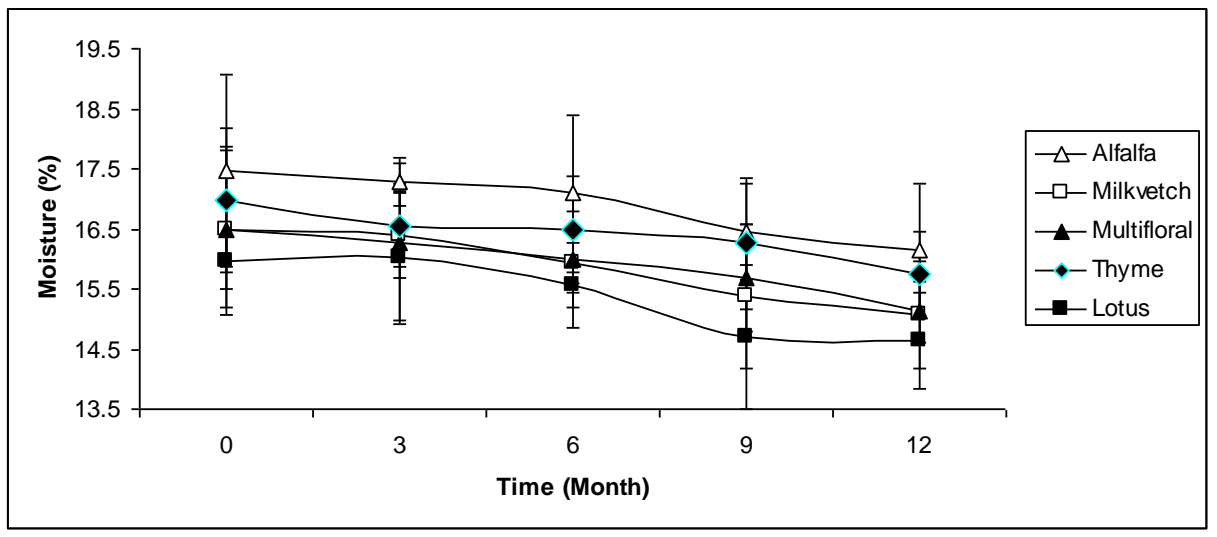

Fig. 3B

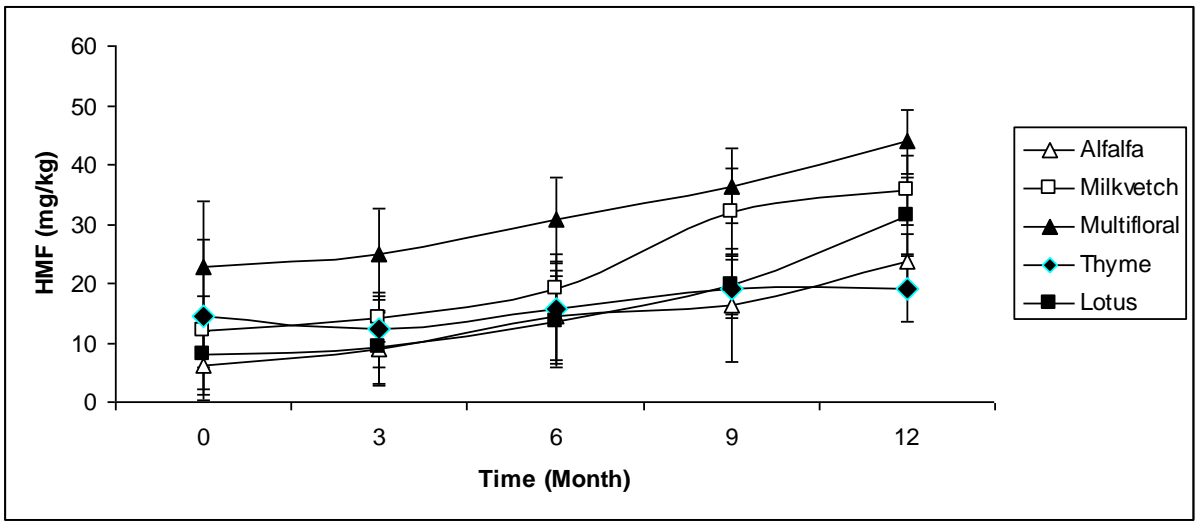

Fig. 3. Changes in moisture (A) and HMF content (B) of honey during storage

The color of honey usually ranges from pale yellow to dark amber and sometimes even green or red tinge [21]. In studied honey samples, the initial color ranged from pale yellow to Amber. The brightest samples were alfalfa honey, almost pale yellow with the lowest Pfund value $(48.14 \pm 5.9 \mathrm{~mm})$. Milkvetch honey was yellow to pale brown. Multifloral honey were very colorful, from yellow to brown or sometimes light amber. The color of Thyme honey was amber with a dark green tinge. Lotus honey was dark amber with the highest Pfund value (98.11 $\pm 16.1 \mathrm{~mm}$ ). As previously proved in many studies, color of honey is attributed to the mineral content of honey $[1,7,19]$. In our work as well, darker honey had more ash content and consequently more electrical conductivity.

In all types of honey, color did not change significantly during the first six months of storage. After that, color of the honey increased, with more pronounced increase in the lightcolored honey e.g. alfalfa and milkvetch, compared to dark-colored ones (Fig. 4A). Color 
enhancement could be due to light exposure, reduction in the moisture content and consequently increase in the concentration of the components responsible for the honey's color, such as minerals.

The method of Folin-Ciocalteu's is, largely used to evaluate total phenolics in many different samples, including honey. Phenolic compounds include different subclasses (flavonoids, phenolic acids, stilbenes, lignans, tannins and oxidized polyphenols) displaying a large diversity of structures, some of which may interfere in the assay. For instance, ascorbic acid is a widespread reducing agent that can interfere in the Folin-Ciocalteu reaction. Other reducing substances such as some sugars and amino acids could also interfere [22]. Honey samples usually contain some of these compounds which can lead to an increase in the absorbance values and therefore overestimation of the phenolic compounds. Our results showed that the total phenolic content (mg tannic acid/kg honey) varied greatly among the honey types. The lowest initial value was determined in alfalfa honey, where the average result of five samples was $263.1 \pm 41.31 \mathrm{mg} / \mathrm{kg}$, rising further in milkvetch and multifloral honey. The highest initial values were obtained for thyme and lotus honey, $567.4 \pm 63.9$ and $556.2 \pm 49.6 \mathrm{mg} / \mathrm{kg}$, respectively.

As shown in Fig. 4B, during the storage period, the total phenolic contents of all types of honey did not change significantly during the first three months of storage. After that, phenolic contents were decreased in all types of honey, from less than $30 \%$ decrease in multifloral honey to more than $60.0 \%$, in lotus honey.

According to Wang et al. (2004), after six months of storage, total phenolic content decreased by $25 \%$ in clover honey and by $17 \%$ in buckwheat honey [23]. Furthermore, Saric et al. (2012), demonstrated that after one year of storage, total phenolic content decreased by 91.8 $\%$ in acacia honey, and by $88.6 \%$ in multifloral honey [24].

Fig. 4A

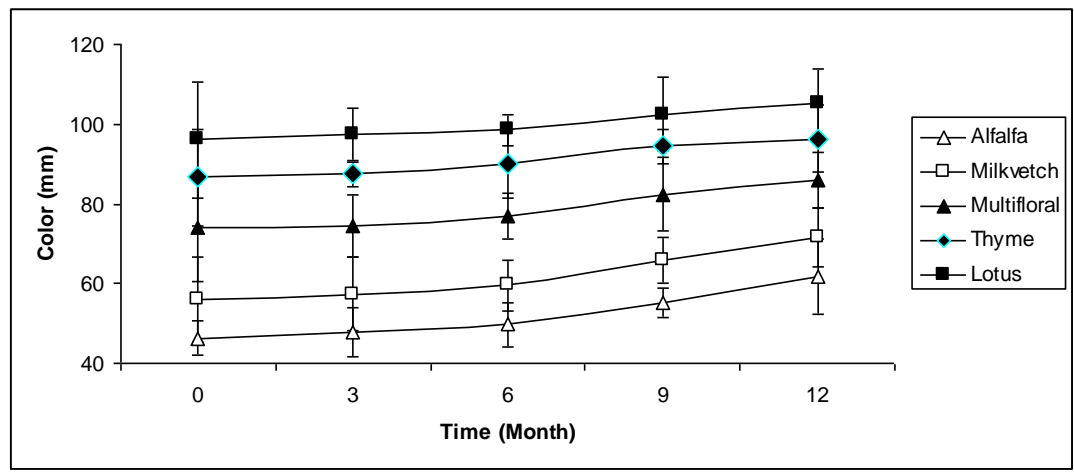

Fig. 4B

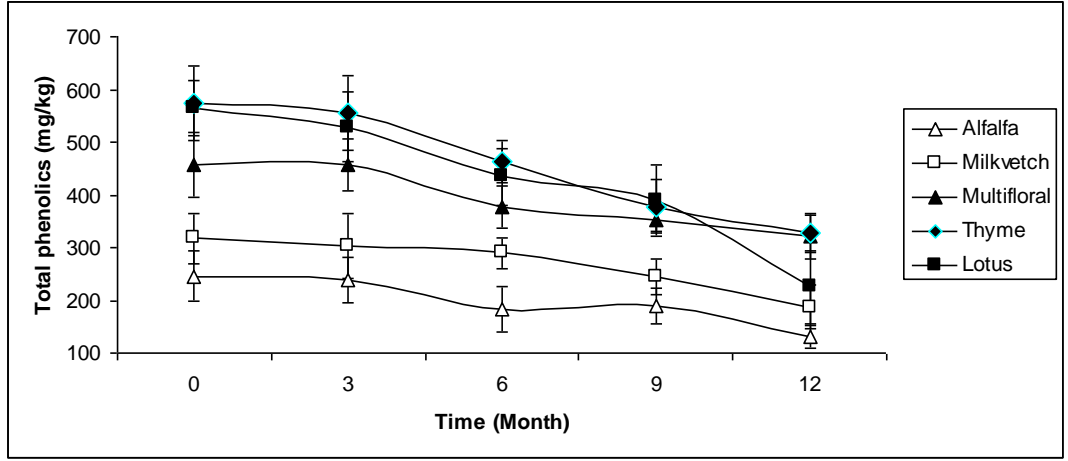

Fig. 4. Changes in color (A) and total phenolic content (B) of honey during storage 
In the recent years there has been an increasing interest in determination of the antioxidant activity of honey. The quantity of the components responsible for antioxidant activity of honey varies widely according to the floral and geographical origin of honey. Processing, handling and storage of honey affect antioxidant activity of honey only to a minor degree [23, 25, 26]. Many methods have been used for determining the antioxidant activity of honey, e.g., the DPPH (2,2diphenyl-1-picrylhydrazyl) method, the FRAP (ferric-reducing/antioxidant power) assay, the ORAC (oxygen radical absorbance capacity) assay, and TEAC (Trolox equivalent antioxidant activity) assay.

In the present study, we used the DPPH method to determine the percent of radical scavenging activity (\% RSA) of honey samples. This means that the higher is the \% RSA value of the honey, the higher is its antioxidant activity. The lowest initial RSA values were $19.24 \pm$ 6.7 and $24.1 \pm 7.6 \%$ for alfalfa and milkvetch honey and the highest was $65.11 \pm 17.4 \%$ for thyme honey (Fig. 5A).

During the storage period, the RSA decreased in all types of honey. As shown in Fig. 5A, after one year storage of honey, RSA decreased by $54.9 \%$ in alfalfa; $73.3 \%$ in milkvetch; 38.92 $\%$ in multifloral; $55.44 \%$ in thyme and $63.8 \%$ in lotus honey.

Almost the same results have been reported previously for multifloral honey; $37.1 \%$ decrease in DPPH radical scavenging activity during one-year of storage [24]. On the other hand, very high rate of RSA decline $(811.7 \%)$ was also reported for acacia honey at the same time of storage [24].

Fig. 5A

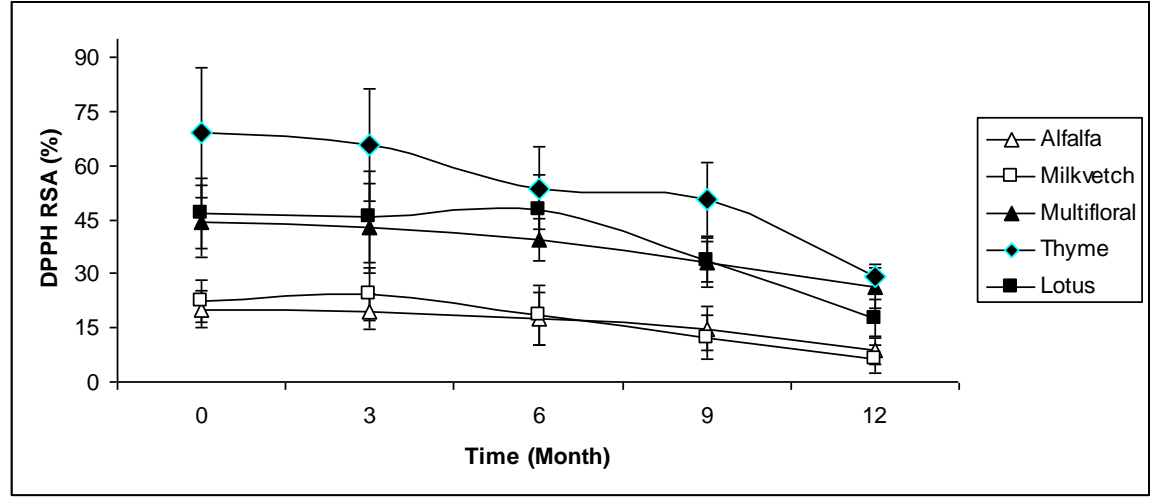

Fig. 5B

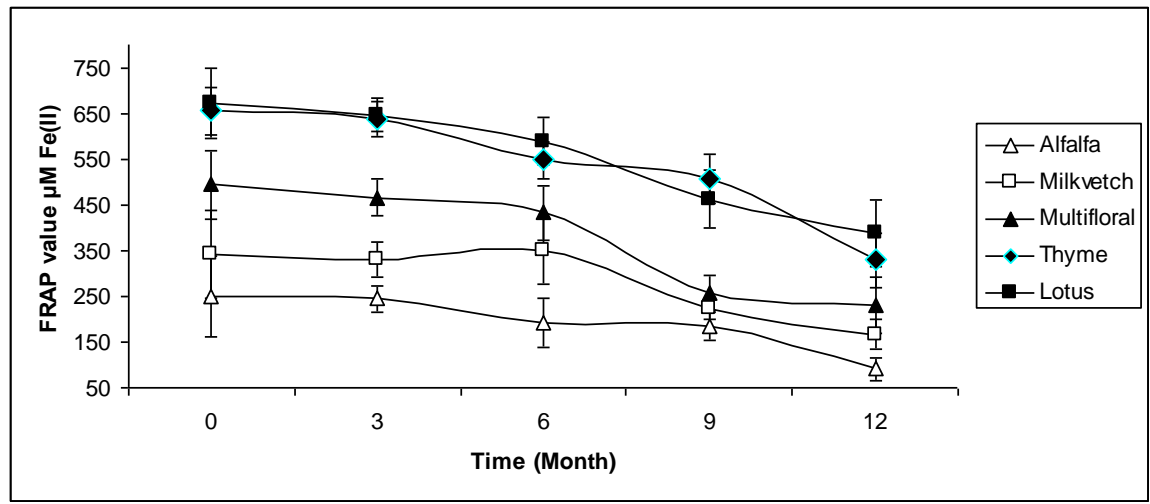

Fig. 5. Changes in DPPH radical scavenging activity (A) and FRAP value (B) of honey during storage 
Since the DPPH assay procedure reflects only the activity of water-soluble antioxidants [27], FRAP assay was used for the evaluation of the total antioxidant activity. Our results showed that, the initial antioxidant activity for different types increased in the order: alfalfa $<$ milkvetch < multifloral < thyme < lotus honey. Alfalfa honey had an average FRAP value of $274.1 \pm 86.41$ $\mu \mathrm{M}$ Fe(II), while the highest FRAP values were reached by Iranian lotus and thyme honey, 685.0 \pm 71.3 and $629.1 \pm 47.6 \mu \mathrm{M} \mathrm{Fe}(\mathrm{II})$, respectively.

During the storage period, the FRAP values of all types of honey did not change significantly during the first three months of storage. However, at the end of the storage time, significant decreases were observed in the FRAP values of all types of honey $(\mathrm{P} \leq 0.05)$. As shown in Fig. 5B, FRAP values decreased by $67 \%, 52.7 \%, 47.7 \%, 43.29 \%$ and $55.01 \%$ in alfalfa, milkvetch, thyme, lotus and multifloral honey, respectively. According to Saric et al. (2012), during one-year of storage, FRAP values decreased by $428.0 \%$ in acacia honey and by $72.5 \%$ in multifloral honey.

\section{CONCLUSION}

This study aimed to evaluate the changes in physicochemical and antioxidant properties of honey during one year of storage. As expected, physicochemical and antioxidant properties of different types of honey are subject to change during the storage period. Changes made in some of these characteristics are merely important from the standpoint of compliance with national and international legal limits, e.g. $\mathrm{pH}$, acidity, HMF content, etc. However, from the nutritional point of view, decrease in the antioxidant capacity of honey is of importance. Our results showed 38.92-73.3 \% decrease in DPPH radical scavenging activities and 43.29-67.0 \% decrease in FRAP values of different types of honey during one-year of storage at room temperature. These levels of reduction in antioxidant capacity could certainly affect the health benefits of honey.

List of abbreviations: Electrical conductivity (EC), Hydroxymethylfurfural (HMF), Radical scavenging activity (RSA), Ferric reducing antioxidant power (FRAP), Analysis of variance (ANOVA), Iranian national standards organization (INSO), 2,2-diphenyl-1-picrylhydrazyl (DPPH), oxygen radical absorbance capacity (ORAC), Trolox equivalent antioxidant activity (TEAC), Association of Official Analytical Chemists (AOAC).

Competing interests: The authors declared no conflict of interest.

Authors' contributions: Mehdi Zarei conducted the research and wrote the manuscript; Ali Fazlara conducted statistical analysis, Nasim Alijani performed the experiments; All authors take responsibility for the final content of the manuscript. 
Acknowledgements and funding: This study was supported by the research grant provided by Shahid Chamran University of Ahvaz. The authors would like to thank Mrs. P. Esfahani for her kind assistance.

\section{REFERENCES}

1. Bertoncelj J, Dobersek U, Jamnik M, Golob T: Evaluation of the Phenolic Content, Antioxidant Activity and Colour of Slovenian Honey. Food Chemistry 2007, 105:822828.

2. Ferreira ICFR, Aires E, Barreira JCM, Estevinho LM: Antioxidant activity of Portuguese honey samples: Different contributions of the entire honey and phenolic extract. Food Chemistry 2009, 114:1438-1443.

3. Gomes S, Dias LG, Moreira LL, Rodrigues P, Estevinho L: Physicochemical, microbiological, and antimicrobial properties of commercial honey from Portugal. Food and Chemical Toxicology 2010, 48(2):544-548.

4. National Honey Board. Honey-Health and Therapeutic Qualities. National Honey Board 2003, Longman 28.

5. Iglesias MT, de Lorenzo C, Polo MC, Martin-Alvarez PJ, Pueyo E: Usefulness of amino acids composition to discriminate between honeydew and floral honey. Application to honey from a small geographic area. Journal of Agricultural and Food Chemistry 2004, 52:84-89.

6. Al ML, Daniel D, Moise A, Bobis O, Laslo L, Bogdanov S: Physicochemical and bioactive properties of different floral origin honey from Romania. Food Chemistry 2009, 112:863-867.

7. Habib HM, Al Meqbali FT, Kamal H, Souka UD, Ibrahim WH: Physicochemical and biochemical properties of honey from arid regions. Food Chemistry 2014, 153:35-43.

8. Truzzi C, Illuminati S, Annibaldi A, Finale C, Rossetti M, Scarponi G: Physicochemical Properties of Honey from Marche, Central Italy: Classification of Unifloral and Multifloral Honey by Multivariate Analysis. Natural Product Communications 2014, 9(11):1595-1602.

9. Sancho MT, Muniategui S, Huidobro JF, Simal J: Evaluating soluble and insoluble ash, alkalinity of soluble and insoluble ash and total alkalinity of ash in honey using electrical conductivity measurements at $20^{\circ} \mathrm{C}$. Apidologie 1992, 23:291-297.

10. AOAC International: Official Methods of Analysis. 17th edition. Association of Official Analytical Chemists: Arlington, TX, 2000. 
11. Singleton VL, Orthofer R, Lamuela-Raventos RM: Analysis of total phenols and other oxidation substrates and antioxidants by means of Folin- Ciocalteu reagent. Methods in Enzymology 1999, 299:152-178.

12. Brand-Williams W, Cuvelier ME, Berset C: Use of a free radical method to evaluate antioxidant activity. LWT - Food Science and Technology 1995, 28:25-30.

13. Dudonne S, Vitrac X, Coutiere P, Woillez M, Merillon JM: Comparative study of antioxidant properties and total phenolic content of 30 plant extracts of industrial interest using DPPH, ABTS, FRAP, SOD, and ORAC assays. Journal of Agricultural and Food Chemistry 2009, 57(5):1768-1774.

14. Benzie IFF, Strain JJ: The ferric reducing ability of plasma (FRAP) as a measure of “Antioxidant Power": The FRAP assay. Analytical Biochemistry 1996, 239:70-76.

15. Feas X, Pires J, Iglesias A, Estevinho ML: Characterization of artisanal honey produced on the Northwest of Portugal by melissopalynological and physico-chemical data. Food and Chemical Toxicology 2010, 48:3462-3470.

16. INSO. Honey: Specification and test methods. Iranian national standards organization 2013, No:92, 7th rev.

17. Terrab A, Recalames AF, Hernanz D, Heredia FJ: Characterisation of Spanish thyme honey by their physicochemical characteristics and mineral contents. Food Chemistry 2004, 88:537-542.

18. Krell R: Codex Standard for Honey. In Value-added Products from Beekeeping. FAO: Rome, Italy; 2001.

19. El Sohaimy SA, Masry SHD, Shehata MG: Physicochemical characteristics of honey from different origins. Annals of Agricultural Sciences 2015, 60(2):279-287.

20. Fallico B, Arena E, Verzera A, Zappala M: The European food legislation and its impact on honey sector. Accreditation and Quality Assurance 2006, 11:49-54.

21. Bogdanov S, Ruoff K, Oddo LP: Physico-chemical methods for the characterisation of unifloral honey: a review. Apidologie 2004, 35:S4-S17.

22. George S, Brat P, Alter P, Amiot MJ: Rapid determination of polyphenols and vitamin C in plant-derived products. Journal of Agricultural and Food Chemistry 2005, 53:1370-1373.

23. Wang XH, Gheldof N, Engeseth NJ: Effect of processing and storage on antioxidant capacity of honey. Journal of Food Science 2004, 69:96-101.

24. Sharit G, Markovich K, Major N, Krpan M, Urshulin-Trstenjak N, Hrushkar M, Vahchit N: Changes of antioxidant activity and phenolic content in acacia and multifloral honey during storage. Food Technology and Biotechnology 2012, 50(4):434-441. 
25. Gheldof N, Engeseth NJ: Antioxidant capacity of honey from various floral sources based on the determination of oxygen radical absorbance capacity and inhibition of in vitro lipoprotein oxidation in human serum samples. Journal of Agricultural and Food Chemistry 2002, 50:3050-3055.

26. Turkmen N, Sari F, Poyrazoglu ES, Velioglu YS: Effects of prolonged heating on antioxidant activity and colour of honey. Food Chemistry 2005, 95:653-657.

27. Aljadi AM, Kamaruddin MY: Evaluation of the phenolic contents and antioxidant capacities of two Malaysian floral honey. Food Chemistry 2004, 85:513-518. 